\title{
Evaluation Method and Simulation of Accounting Integrity in View of Grey Correlation Model
}

\author{
Cai Li iD \\ School of Management, Henan Institute of Technology, Xinxiang, Henan 453003, China \\ Correspondence should be addressed to Cai Li; jiayoulicai@hait.edu.cn
}

Received 14 December 2021; Revised 10 January 2022; Accepted 11 January 2022; Published 29 January 2022

Academic Editor: Miaochao Chen

Copyright (c) 2022 Cai Li. This is an open access article distributed under the Creative Commons Attribution License, which permits unrestricted use, distribution, and reproduction in any medium, provided the original work is properly cited.

\begin{abstract}
Accounting dishonesty is still a problem that is far from being solved, both in theory and in practice. In the existing research on accounting dishonesty, scholars mostly analyze the causes and countermeasures of the lack of accounting integrity from the aspects of external accounting system and internal corporate governance and fail to establish a theoretical system and analytical framework for accounting integrity analysis. This limitation inevitably makes the analysis stay on the surface of things with lack of a deep grasp of its essential problems. Through the study of the relevant literature, the grey correlation model can sort the proportion of the factors affecting accounting integrity and get the primary and secondary factors affecting accounting integrity, so as to put forward more targeted countermeasures to solve the problem of accounting integrity. Based on this, this paper uses the method of combining theory with practice to study the problem of accounting integrity. Combined with the current situation of accounting integrity, this paper uses the grey correlation model to sort the proportion of the factors affecting accounting integrity, analyzes its specific reasons, and finally puts forward the measures to solve the dilemma of accounting integrity according to the analysis results. In view of the problems of enterprise accounting integrity, it is necessary to strengthen the publicity and education of accounting practitioners' integrity system. Accelerate the construction of the legal system of accounting integrity and promote the legislation of accounting integrity. A full-time organization for accounting integrity evaluation should be established to measure the accounting integrity of enterprises by using reasonable evaluation means and methods, clear and standardized evaluation contents, and integrity level standards.
\end{abstract}

\section{Introduction}

The business environment of today's society is in an increasingly complex and rapid change. The expanding capital and commercial market, the increasing number of largescale mergers and acquisitions, and the international operation of enterprises continue to appear. With the emergence of highly specialized computer accounting and settlement systems, off-balance sheet entities, and financial derivatives, both inside and outside enterprises are facing a more complex modern financial environment. It is conceivable that in such an environment, risks are everywhere. With the increase of competitive pressure, the increase of business variables, and the strong desire for interests, enterprise management fraud has been heard from time to time, and false account scandals have broken out continuously. Enron, WorldCom, Xerox and domestic Zheng Baiwen, liming shares, Yin Guangxia, and Meggitt have all experienced amazing financial fraud cases. As an independent auditor, accounting firms also "lose everything," and the well-known Andersen and Zhongtianqin have sadly withdrawn from their familiar audit market. It can be said that the CPA industry has entered an unprecedented era of "integrity dilemma" and "litigation explosion" [1-5].

In the market economy, audit is a high-risk profession, because certified public accountants need to bear the loss of audit risk, so certified public accountants and accounting firms strive to control the risk with high-quality audit. However, in the process of China's economic system reform from planned economy to market economy, there has been no spontaneous demand for high-quality audit. On the 
contrary, accounting firms adhering to high audit quality are easy to lose "bad money drives good money" in the market. The fundamental reason is that China's audit is a low-risk profession. Institutional defects make the main audit risk losses ultimately borne by the public. This has led to the widespread business philosophy of "emphasizing development, neglecting quality" and "emphasizing relationship, neglecting technology" in Chinese accounting firms. Ideological contempt, coupled with the backwardness of management technology, has greatly weakened the risk-carrying capacity of Chinese accounting firms and also caused a serious lack of their core competitiveness. Therefore, when changes in the objective environment force certified public accountants to take audit risks, the vulnerability of Chinese accounting firms is exposed in Figure 1.

As a business language, accounting information is not only the necessary information for the economic communication of market economic subjects but also an important basis for enterprise stakeholders to make economic decisions. The authenticity and effective disclosure of accounting information is the basic requirement for the healthy development of capital market and the effective operation of market economy. However, up to now, the distortion of accounting information is widespread. The lack of enterprise integrity has become an obstacle to economic development. The society calls for integrity. Accounting integrity has become a main aspect of the society's requirements for the integrity of market economy [6-12].

The distortion of accounting information is also an international and historical problem. It has always been a key research topic in the world accounting circles, and it has always been a major problem to be solved by the regulatory departments of governments all over the world. However, all kinds of accounting information distortion have been perplexing countries all over the world. Needless to say, even the United States, which boasts the most perfect market economy and the most sound legal mechanism, has been plagued by accounting scandals in recent years, and the number of accounting fraud is probably unique in the world [13-15].

The importance of accounting information and the seriousness of accounting information distortion have attracted the attention of accounting theorists, practitioners, and relevant government departments all over the world. The research literature on the distortion of accounting information has been voluminous. However, the real problem is that accounting scandals are almost as prosperous as the research on them, and it is difficult to find signs of improvement in the distortion of accounting information recently. The development of things has its own internal reasons and logic, and the distortion of accounting information is no exception. No matter how deep the research on accounting information distortion is, as long as false accounting information still exists in the market and affects the development of social economy and the optimal allocation of social resources, as long as the problem of accounting information distortion remains a problem, it shows that accounting information distortion has not been effectively solved, and the research and exploration of this problem can not stop. Its research also has academic significance and theoretical value. Although the relevant research on accounting information distortion and its governance has been quite rich, from the current reality of serious distortion of accounting information quality, the problem of accounting dishonesty is far from being solved in theory or in practice. Therefore, the research on this problem is not too much, but too little [16-19].

Compared with folk self-discipline, the government-led independent supervision model has more advantages in solving market failure and improving information quality. Liu Minghui and others believe that as an institutional arrangement, the overall efficiency and effect of accounting supervision are jointly determined by the three elements of the system, formal rules, informal constraints, and their implementation mechanism. On this basis, they put forward the improvement and Improvement Countermeasures of the accounting supervision system of listed companies in China. Using a two-stage dynamic game model, Ping Xinqiao and others proved that the interval of the event of "purchasing independent accounting principles" in the information disclosure of Chinese listed companies is a function of the audit probability, punishment, and the refinancing qualification of listed companies stipulated by the CSRC. Wu Liansheng studied the optimal accounting supervision by establishing a two-stage dynamic game model and solving it. It is found that the violation degree of the accounting rule executor is inversely proportional to the punishment, the executor's discount factor, and the government's supervision probability, while the government's accounting supervision is inversely proportional to the punishment, the square of the executor's discount factor, and the government's supervision. The basic conclusion is that effective accounting supervision requires additional costs. The government's optimal postaccounting supervision is to control the accounting fraud of some accounting rule executors within a certain range. The only measure to control the fraud of accounting executors who attach great importance to the current income is to improve the timeliness of accounting supervision. There is a priority order for the implementation conditions of effective accounting supervision. First, distinguish different types of accounting rule executors, secondly, distinguish the punishment of violation that accounting rule executors can really perceive, and then choose the optimal supervision strength. Discuss whether the accounting rules can be effectively implemented directly from two aspects: the cost and income of the implementation of accounting rules. Yao Haixin and others analyzed the accounting supervision of listed companies from the perspective of incomplete information static game, theoretically revealed the behavior motivation and game equilibrium results of listed companies, intermediary departments, and supervision departments, and explained the selection behavior and interaction mechanism of various actors under a given institutional arrangement [20-23]. Zhang et al. propose a tripartition state alphabet-based sequential pattern (Tri-SASP) for MTS, given set of states is partitioned into positive (POS), negative (NEG), and boundary (BND) regions. Hongjiang Cui improves the 


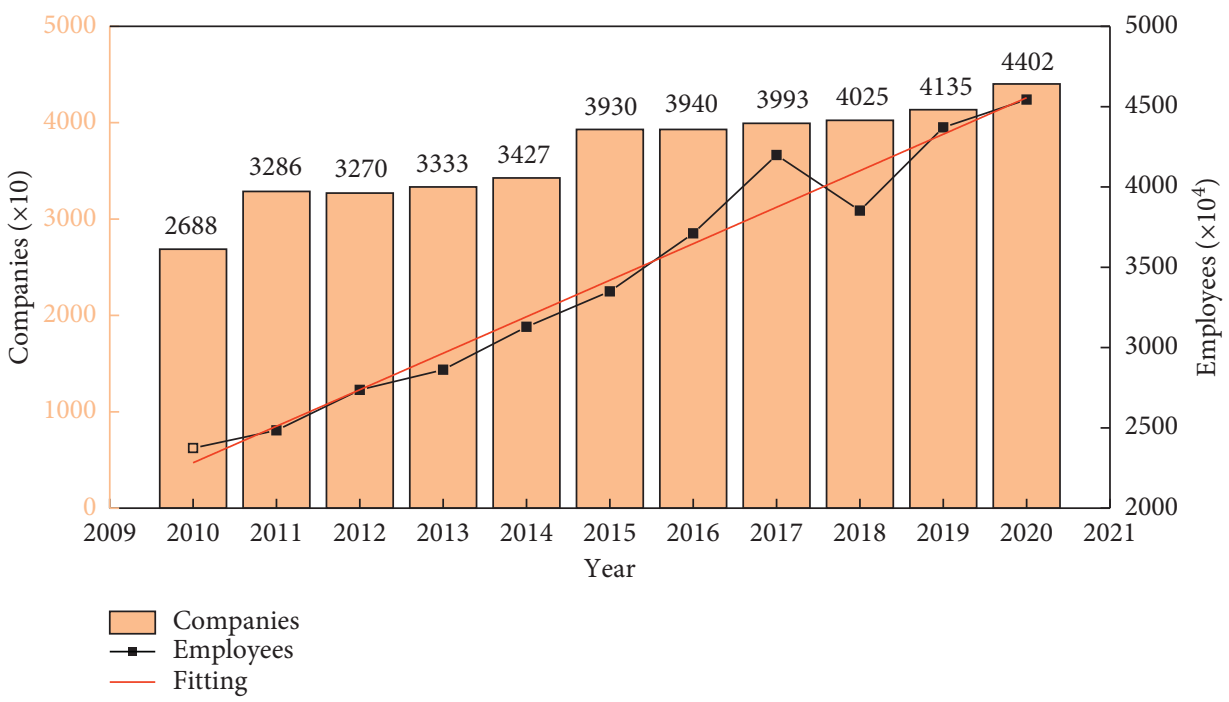

FIGURE 1: Relationship between enterprises and employees.

diagnosis accuracy and solves the weak fault signal of rolling element of rolling bearings due to long transmission path, a novel fault diagnosis method based on variational mode decomposition (VMD) and maximum correlation kurtosis deconvolution, and a new advancing coupled multistable stochastic resonance method, with two first-order multistable stochastic resonance systems, namely, CMSR, is proposed to detect motor bearing faults $[24,25]$.

For the research on the quality of accounting information such as accounting fraud, some people have made a new research attempt from the opposite of accounting dishonesty-accounting integrity. Although accounting dishonesty and integrity can be regarded as two aspects of the same coin, the research on accounting integrity is not synonymous and repeated in the research. The perspective of accounting fraud and other information distortion behaviors from the perspective of accounting integrity can surpass the limitation that the behavior decision of rational economic man only depends on the calculation of economic interests in economics and bring more ethical, moral, customs, and cultural factors into the rational analysis framework of accounting integrity. In reality, there is a sharp opposition between ethical norms and real norms in the space of moral freedom, which leads to the problem of accounting fraud. Only by making the unit leaders the only person responsible for accounting law hopes to truly establish the principle of good faith of Chinese accounting.

\section{Relevant Theoretical Basis of the Grey Prediction Model}

The grey relational analysis model is an important part of the grey theory system, and it is a method to analyze the correlation of multiple sets of data. Its main analysis principle is to judge the correlation degree between each group of data according to the similarity degree of the changing shape of the data curve. The variation trend of multiple groups of data curves is different. Grey correlation analysis combines mathematical geometry principles to describe the similarity degree of each data sequence and quantifies the strength and order of the correlation between each data sequence through a series of data operations.

In essence, accounting is a contractual relationship. The provision of real accounting information is the external manifestation of the smooth performance of accounting contracts. On the one hand, accounting dynamically measures and reports the performance of the factor-use-right contract and also enables the operator to express the contractual responsibility of fiduciary responsibility. Accounting integrity is an essential requirement for the performance of accounting contracts. Its essence is to require the integrity of the process and results of the performance of accounting contracts, which has two meanings. One is the integrity of the process of accounting contract performance, that is, process integrity. Because of the contractual nature of accounting, the contract reflects a transaction relationship between people. Therefore, the essence of the integrity in the process of contract performance is the integrity requirement for the subject of accounting contract execution. The executive subject of an enterprise's accounting contract is the operator or actual controller. Therefore, accounting integrity first refers to the integrity of the operator. It requires the enterprise to conduct accounting treatment according to the actual economic business, abide by the standards and systems, and firmly handle the economic business in accordance with the requirements of accounting regulations, accounting standards, and accounting systems, and choose the accounting treatment method objectively and fairly according to the content of economic business. Contract subjects and other social investors have reason to believe that the accounting information provided by accounting treatment in accordance with financial regulations and accounting systems is accurate, true, complete, and timely. Accounting standards and systems are the professional agreements of the accounting community on the whole society. The second is the integrity of the performance results of accounting contracts. The ultimate purpose of accounting contract performance is to provide accounting information 
to the outside world. Of course, accounting integrity contains the result of the authenticity of accounting information. That is, the accounting information finally reported by the enterprise must be true, fair, and consistent with the objective economic situation of the enterprise. This is the general understanding and ultimate requirement of the market for accounting integrity. In fact, the process of accounting contract performance is unobservable and verifiable to the outside world. Only the accounting information as the result of accounting contract performance can be observed and verifiable to a certain extent. Taking it as the judgment standard of accounting integrity is in line with the scientific falsification logic. The measurement of accounting integrity by accounting information can be judged through folk audit mechanism and price mechanism in effective market. Therefore, the subject of accounting integrity is enterprise managers, and the object of accounting integrity is enterprise accounting information. The integrity of enterprise managers provides a guarantee for accounting integrity, which is the result of the integrity of the main body of accounting contract. The standard of measuring accounting integrity can be obtained by judging the quality of accounting information, and to explore the decision of accounting integrity must start with the influencing factors of accounting executor's personal integrity.

No matter the interval grey number prediction model, the grey number prediction model of the dual heterogeneous sequence between interval grey number and discrete grey, or the parameter estimation and background value optimization of NGM $(1,1) k$ model and GOM $(1,1)$ model, they are all based on the single-sequence grey prediction model [26-32].

A sequence of

$$
\begin{aligned}
X & =(x(1), x(2), \ldots, x(n)), \\
x(k) & =c e^{a k}(c, a \neq 0), \\
k & =1,2, \ldots, n .
\end{aligned}
$$

$X$ is called homogeneous exponential sequence; if

$$
x(k)=c e^{a k}+b(c, a, b \neq 0), \quad k=1,2, \ldots, n .
$$

Then $X$ is called an inhomogeneous exponential sequence.

Let $X$ be the original sequence:

$$
X^{(0)}=\left(x^{(0)}(1), x^{(0)}(2), \ldots, x^{(0)}(n)\right) .
$$

$D$ is the sequence operator:

$$
X^{(0)} D=\left(x^{(0)}(1) d, x^{(0)}(2) d, \ldots, x^{(0)}(n) d\right) .
$$

The original form of the GM $(1,1)$ model is

$$
x^{(0)}(k)+a x^{(1)}(k)=b, \quad k=1,2, \ldots, n .
$$

The mean value of GM $(1,1)$ model is

$$
x^{(0)}(k)+a z^{(1)}(k)=b \text {. }
$$

Then, the least square estimation parameter column of model $x^{(0)}(k)+a z^{(1)}(k)=b$ satisfies

$$
\widehat{a}=\left(B^{T} B\right)^{-1} B^{T} Y .
$$

The whitening equation or shadow equation is

$$
\frac{d x^{(1)}}{d t}+a x^{(1)}=b .
$$

The solution of the whitening equation $\left(d x^{(1)} / d t\right)+a x^{(1)}=b$ is also called the time response function:

$$
x^{(1)}(t)=\left(x^{(1)}(1)-\frac{b}{a}\right)^{e-a(t-1)}+\frac{b}{a} .
$$

According to the modeling method and construction principle of GM $(1,1)$ model,

$$
\begin{aligned}
z^{(1)}(k) & =\frac{1}{2}\left(x^{(1)}(k)+x^{(1)}(k-1)\right), \\
x^{(1)}(k) & =\frac{1-0.5 a}{1+0.5 a} x^{(1)}(k-1)+\frac{b}{1+0.5 a}, \\
k & =2,3, \ldots, n .
\end{aligned}
$$

Due to the algebraic operation between interval grey number will target grey, grey level increases the number of cumulative index of the interval grey number that cannot fit, difficult to in accordance with the traditional grey prediction model of modeling ideas directly facing the grey forecasting model of interval grey number sequences, so people usually will be bleaching processing interval grey number, according to the information equivalence principle.

There are obvious defects in grey slope correlation and grey area correlation. Figure 2 is an example. It is obvious that the area correlation is used to measure the correlation between sequences, while the slope correlation is used to measure other parameters. Obviously, the correlation degree between the same index factors obtained by different methods is completely opposite. This shows that there are defects in the two methods of calculating correlation degree. The reason is that the slope correlation degree only considers the grey correlation degree from the similarity degree of variation trend of factor curves, while the area correlation degree only considers the grey correlation degree from the similarity degree of variation between factor curves. Obviously, the grey correlation degree between the two factors is related to the similarity degree and the similarity degree of the change trend. The slope correlation degree and area correlation degree are only considered from one side, so problems are inevitable.

\section{Accounting Integrity Assessment}

The occurrence of credit default by accounting practitioners is a random and contagious process. This process can be influenced by macroeconomic factors, such as the economic crisis, when many companies default. Credit risk contagion 


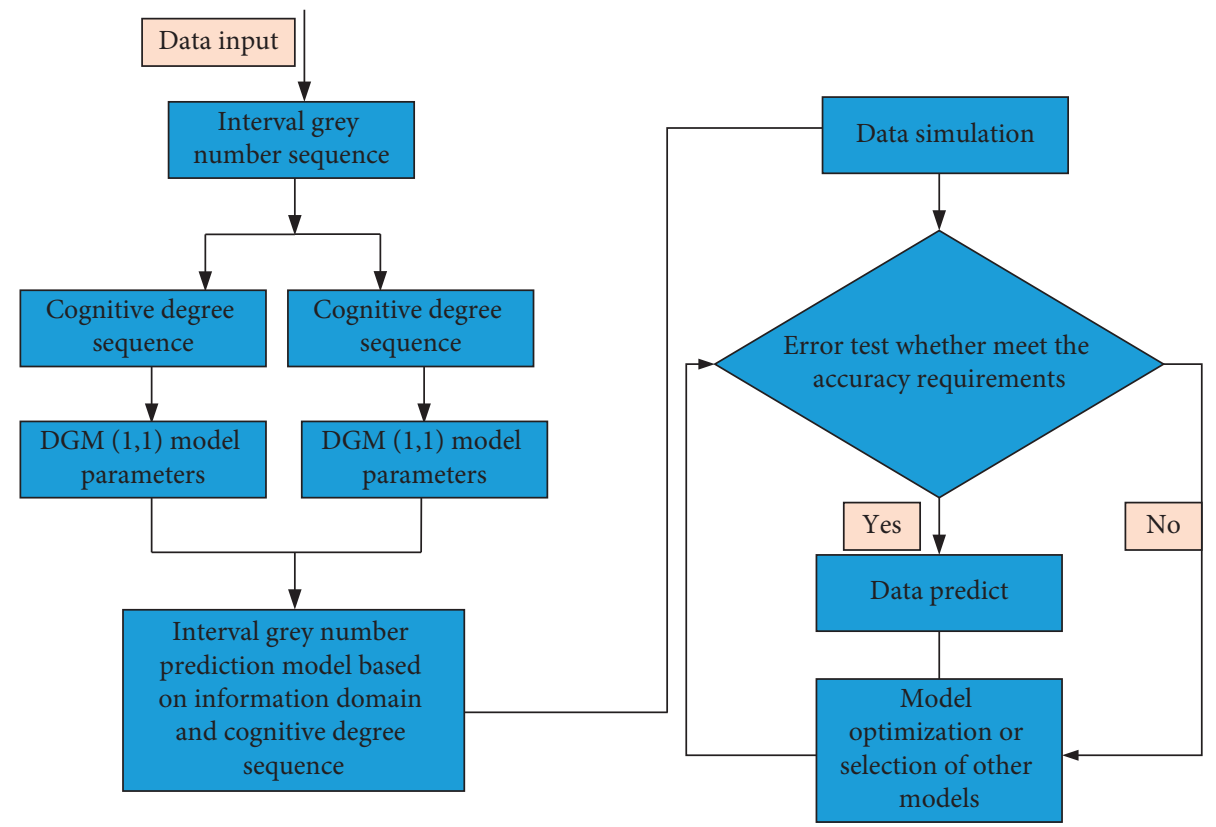

Figure 2: Interval grey number sequence flow.

obviously exists among enterprises with capital, debt, supply, and demand.

The member companies of an enterprise group are associated with each other in terms of asset holding, related transactions, technology, and personnel, and these associated relations of an enterprise group are more subtle or complex than those of ordinary enterprises. As a result, when a subsidiary of the group has a credit default, it is bound to infect or affect the credit risk of its associated parent company or other member companies. Therefore, it is very necessary to study the credit risk contagion caused by association between member companies of enterprise group.

Researchers at home and abroad also began to focus on the study of credit default caused by credit risk contagion, for two reasons: first, credit risk contagion has been proved to exist in empirical analysis, while the traditional credit portfolio model only considers the correlation of macroeconomic factors and ignores the impact of the correlation between enterprises' financial, technical, personnel, and business conditions on credit risk. Therefore, relevant scholars try to model the credit risk contagion relationship on the basis of the original credit portfolio model in order to describe the process or intensity of credit risk contagion. Second, the default rate is very low when the correlation is not considered [33-40].

The intensity of credit risk contagion is not only related to the number of subsidiaries within the group but also related to the qualification of subsidiaries as shown in Figure 3. With the increase of qualified subsidiaries, the intensity of credit risk contagion of the parent company of the group decreases and the probability of credit default becomes smaller after contagion. On the contrary, as the number of unqualified subsidiaries increases, the contagion intensity of the parent company of the group cannot be dispersed, but the probability of credit default of the parent company of the group increases. With the increase of correlation between parent and subsidiary companies, the probability of simultaneous credit default of parent and subsidiary companies increases, and the credit risk contagion intensity between parent and subsidiary companies increases, that is, the credit risk contagion intensity between parent and subsidiary companies is positively correlated with the grey correlation degree between parent and subsidiary companies.

Figures 4 and 5 propose a new method to solve model parameters, which avoids the jump error of model parameter solution from difference equation to differential equation, deduces the solution process of model parameters, and gives the specific expression of model sequence predicted value. It is proved theoretically that the new NGM $(1,1) k$ model can simulate both subexponential growth sequence and completely inhomogeneous exponential growth sequence, and the new $\operatorname{NGM}(1,1) k$ model is the general form of GM $(1,1)$ model. The validity of the new NGM $(1,1) k$ model is verified by numerical examples in existing literature, and the results show that the new $\operatorname{NGM}(1,1) k$ model has higher simulation and prediction accuracy than the NHGM $(1,1) k$ model.

Figure 6 is a diagram of the elements of the interval grey number sequence in the cartesian coordinate system. The unique exponential function can be determined by the upper and lower bounds of the adjacent interval grey numbers, respectively. The graph surrounded by the exponential function is called the grey number layer, and the grey number layer between several adjacent intervals is called the grey number band.

Based on the professional knowledge and practical experience of relevant experts, the model description method in Figures 7 and 8 is used to determine the qualitative comment set and corresponding model of each factor influencing credit risk. 


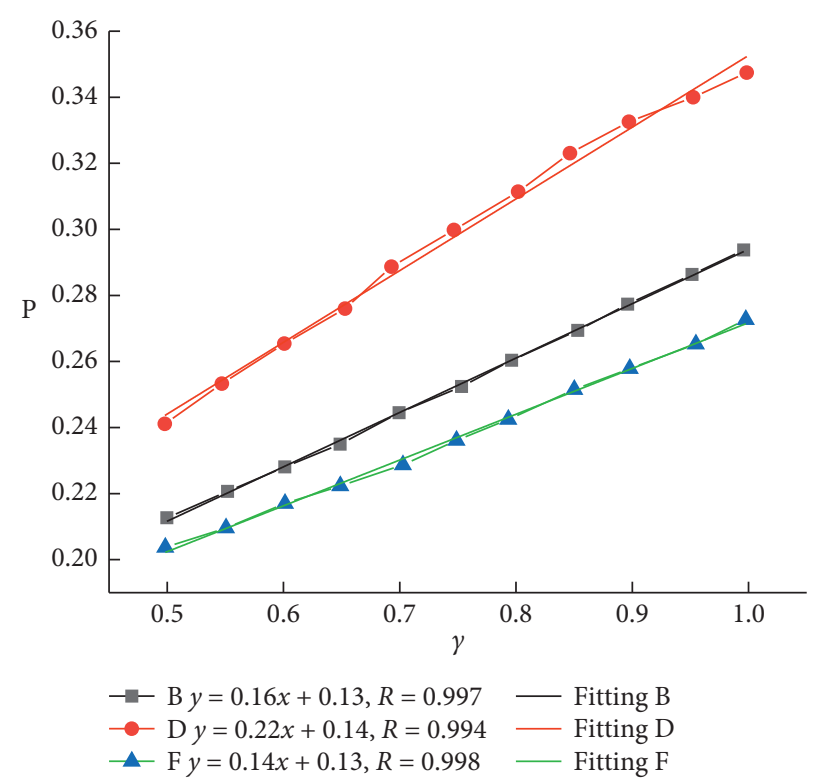

FIGURE 3: Relationship between the grey correlation degree and risk.

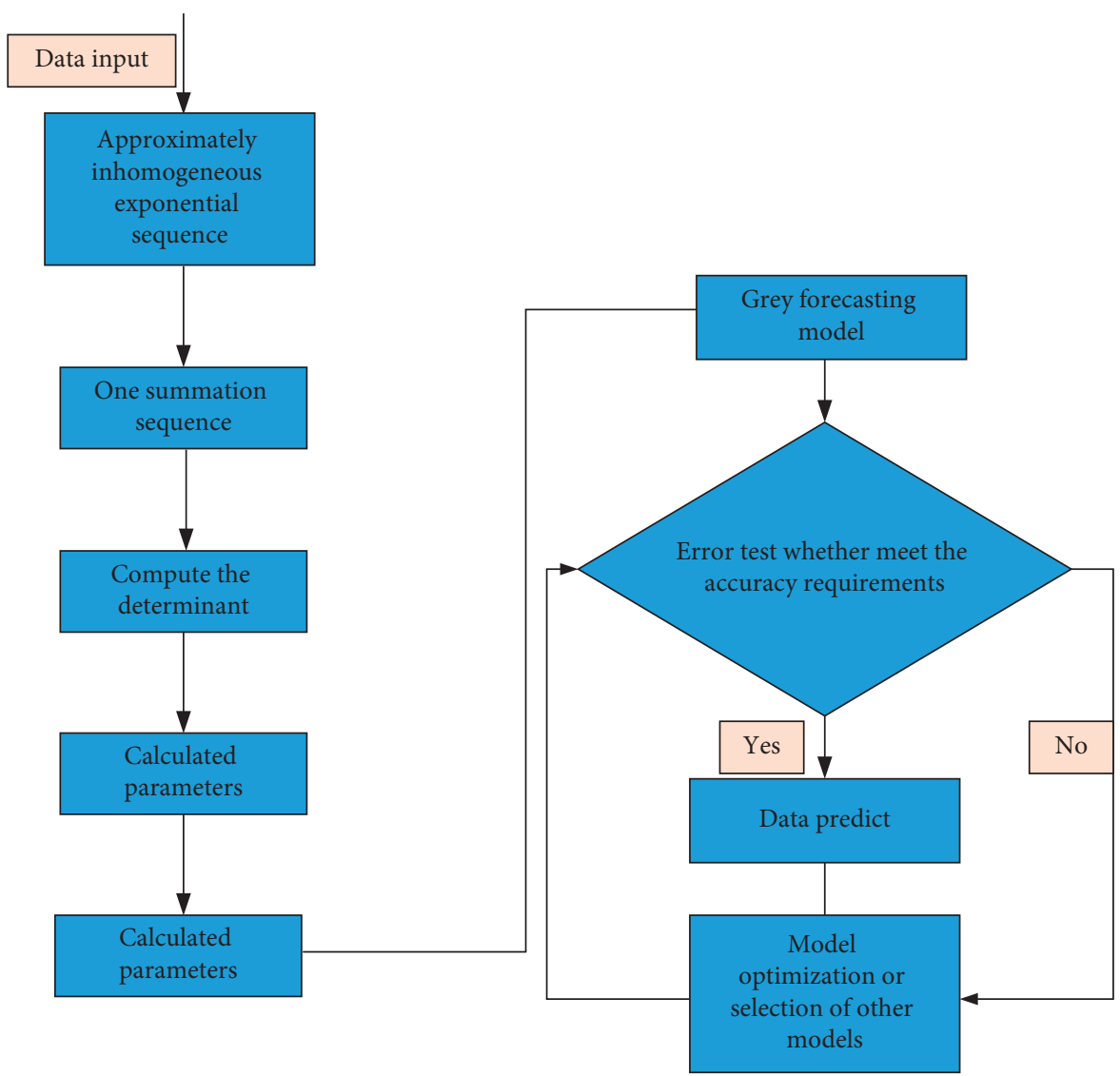

FIGURE 4: Grey prediction model flow.

\section{Accounting Integrity and System Perfection}

As a mandatory arrangement to regulate people's behavior, system determines the behavior norms of market subjects and the specific economic order of the society. As the characteristics of the accounting behavior of the market economy subject, the level of accounting integrity is naturally affected by the institutional arrangements related to 


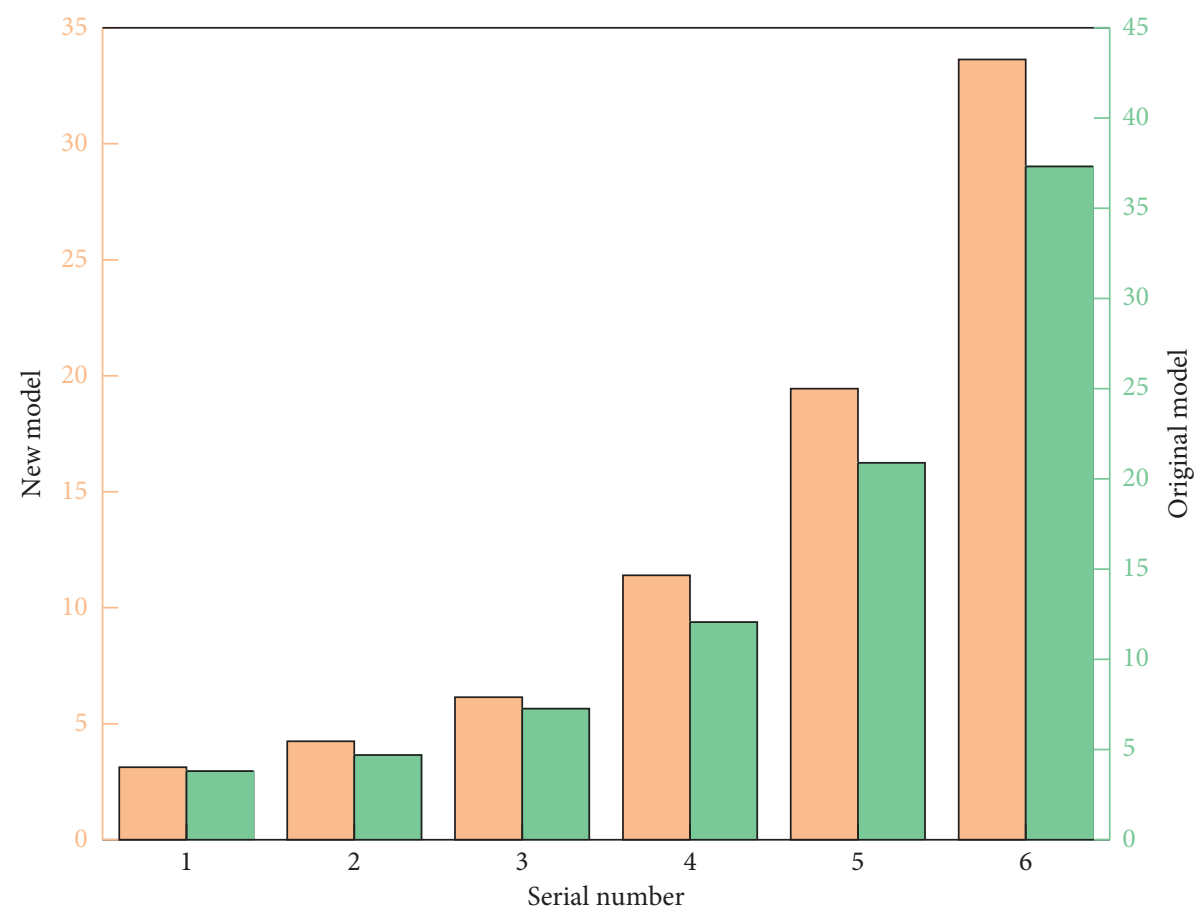

(a)

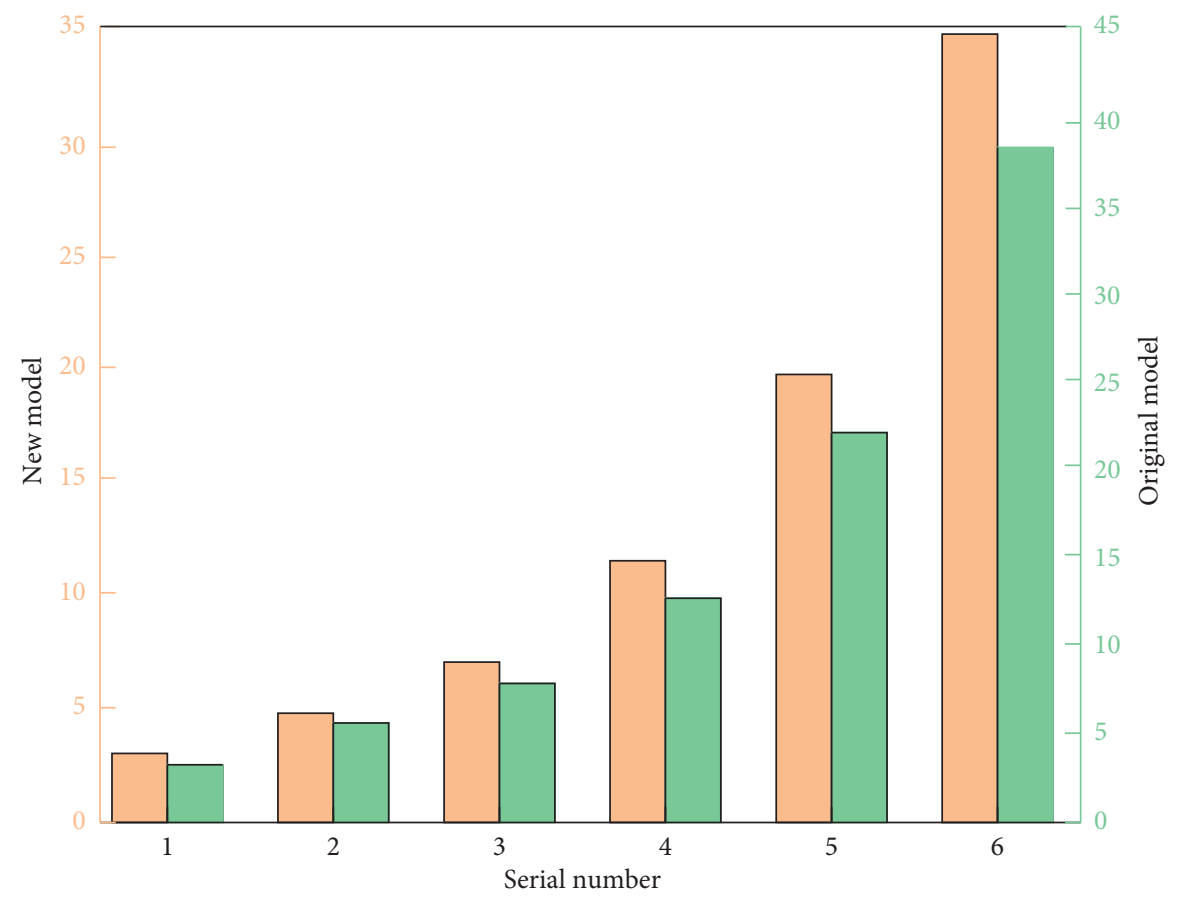

(b)

FIgURE 5: Continued. 


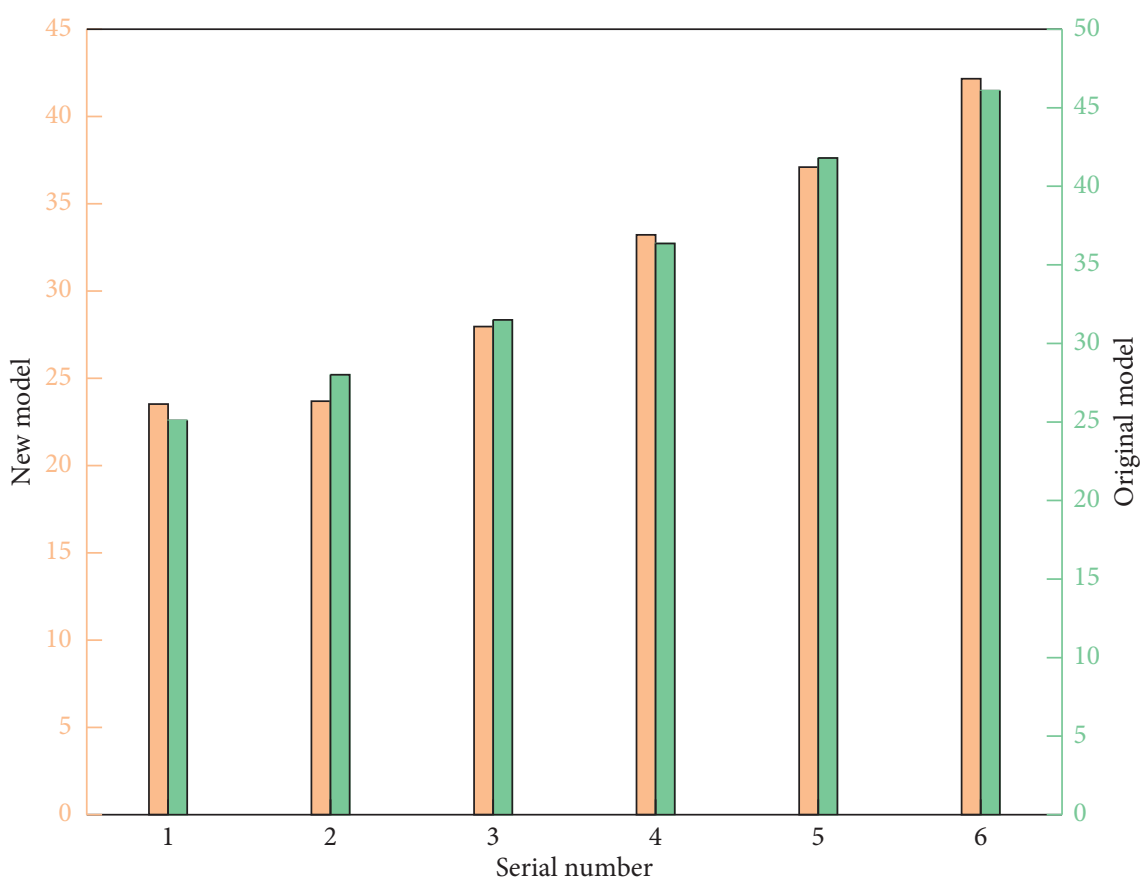

(c)

FIgURE 5: Performance comparison. (a) Inhomogeneous exponential sequence performance. (b) Approximately inhomogeneous exponential sequence performance. (c) Performance comparison chart.

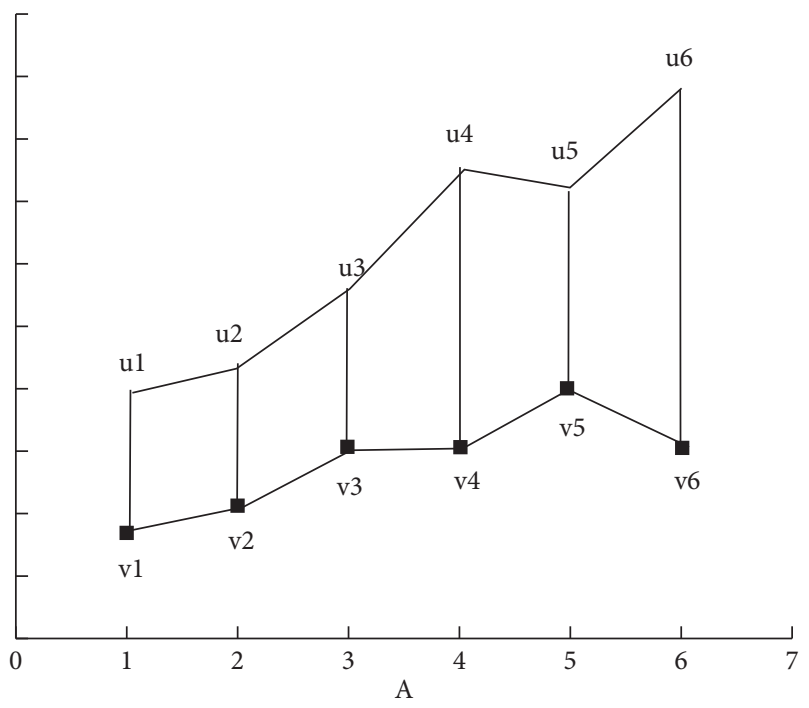

(a)

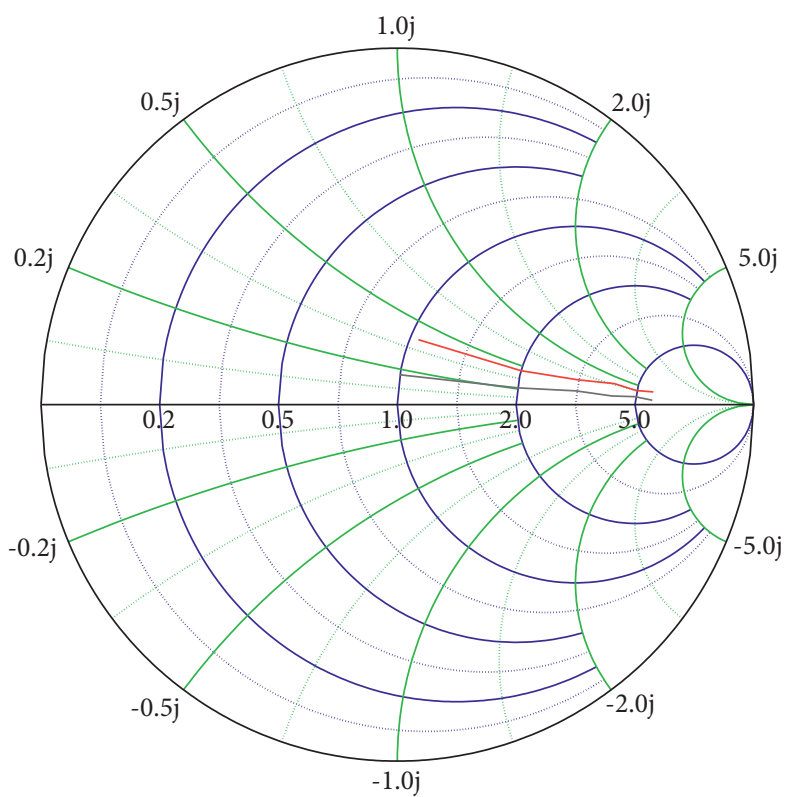

(b)

FIgURE 6: Schematic diagram of the grey layer.

accounting execution. Execute related to accounting and there are many different kinds of formal system arrangement and different level, discussed in this chapter are not prepared to judging the quality of the concrete accounting system, focus on from the angle of the system of accounting sincerity to discuss how to standardize the behavior of the accounting system type, to clarify the influence of different institutional arrangements of accounting integrity mechanism and function way, and to establish and perfect the relevant system provided in reality [41, 42].

The level of accounting integrity is determined by the behavior of the executor of accounting rules as a rational 


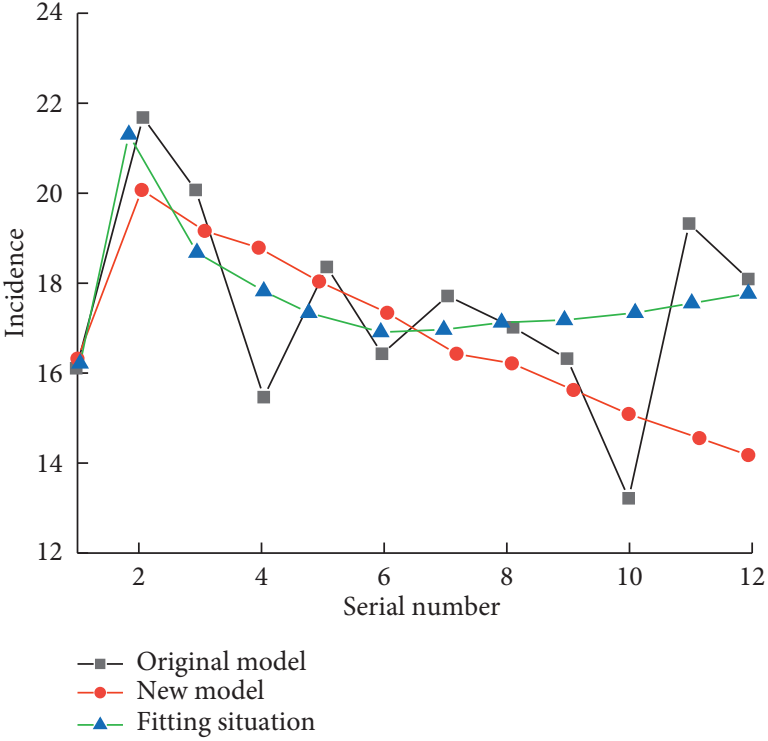

(a)

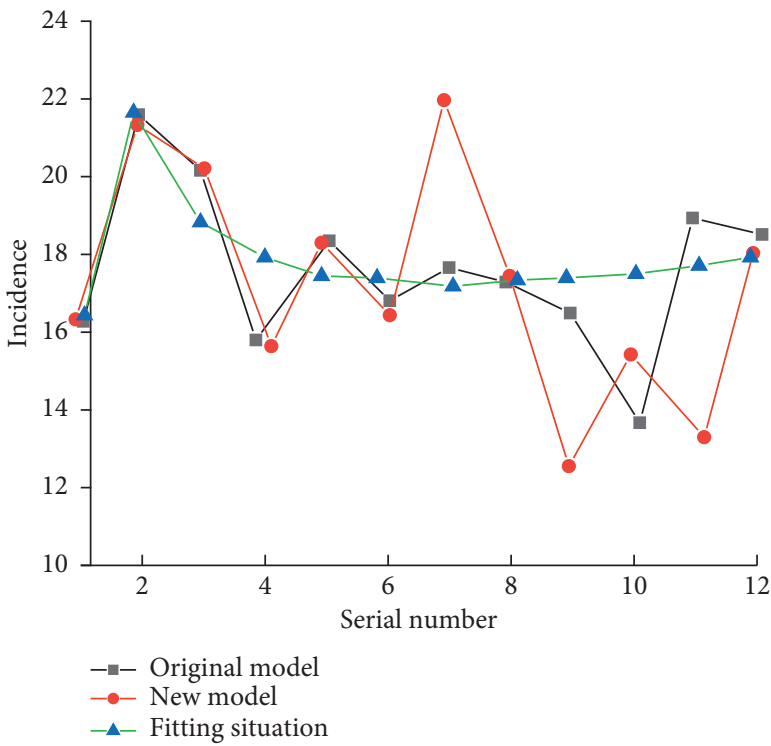

(c)

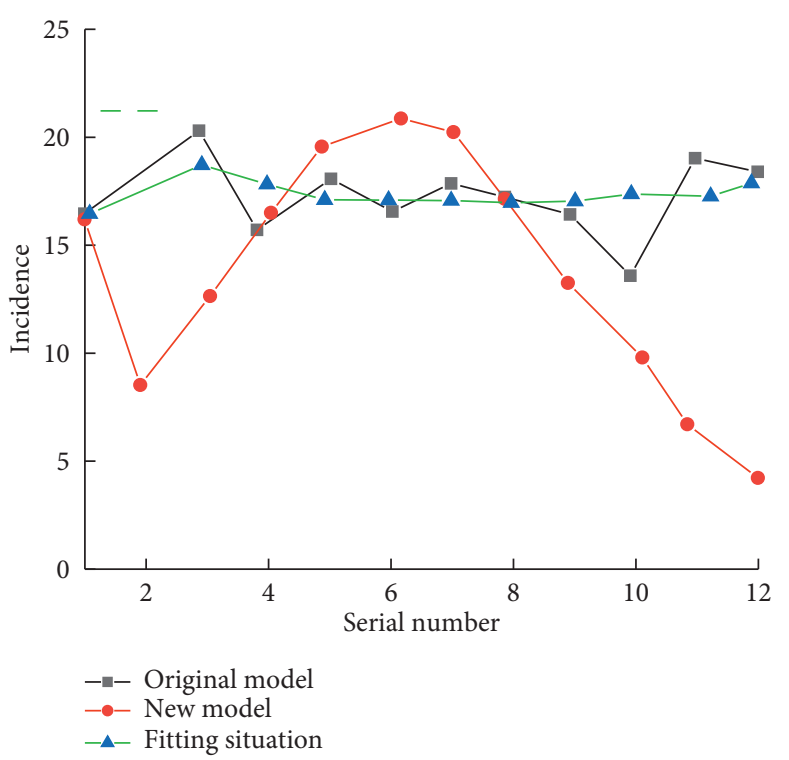

(b)

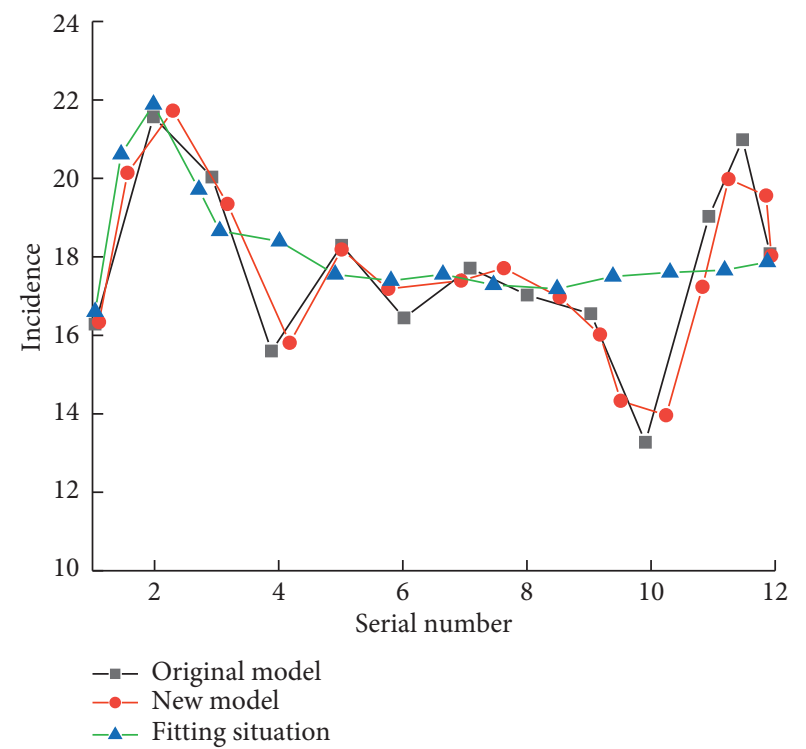

(d)

Figure 7: Comparison of simulation effects.

economic man, and the behavior of the executor is under the environment of social system. The system motivates the actor to abide by the rules and make specific behaviors in line with the system norms and public order by influencing the economic expectations of the actor. The mechanism of the effect of the system on the accounting integrity is mainly through the normative measures and punitive provisions related to the accounting standards to induce the accounting rules of the implementation of the good faith behavior. In this way, the decision of accounting integrity mainly depends on the following two characteristics of the relevant system: one is the degree of perfection of the system as a technical standard, and the other is the efficiency of the system to the interests of actors, that is, the implementation characteristics of the system. The former mainly refers to the accounting system of accounting treatment and disclosure of specific provisions; the latter includes a variety of regulatory systems and other relevant punitive systems. Will affects the relevant institutional arrangements to accounting integrity, although the system has two main aspects of the intersection of the same item system arrangement is related to accounting and involve the violation of the measures, but in general, the influence of accounting integrity system is divided into accounting norms system and accounting regulation system, two aspects.

Different institutional arrangements determine the cost and benefit of accounting integrity of the specific executor. The change of institutional arrangements affects the level of accounting integrity by affecting the cost and benefit structure of accounting integrity of the executor. Since cost 


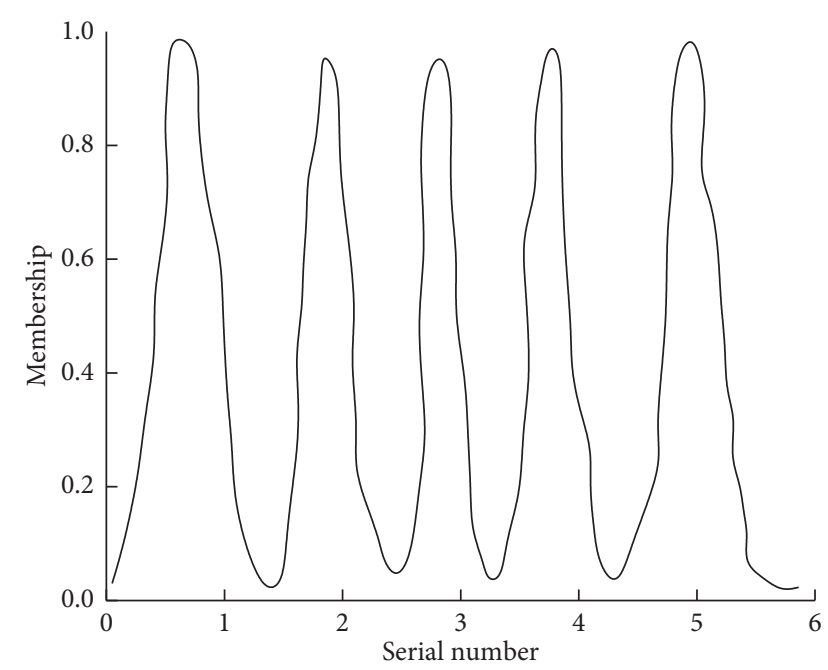

Figure 8: Membership relation.

and benefit are two sides of the same coin, benefit and cost can be mutually explained by the principle of mutual inversion. In order to simplify the analysis, the following is only from the impact of the system on the cost of accounting integrity analysis, so as to conclude the accounting integrity based on the system and its basic theoretical logic in Figure 9.

When building the system, first consider the matching degree with other systems. For the governance of false accounting information, it is not advisable to blindly consider strengthening the construction of accounting standards or solely emphasize the punishment of cheaters. The two should go hand in hand. The role of different institutional arrangements depends on the institutional environment provided by other institutional arrangements. The existence of regulatory critical point shows that when the regulatory system is not in place and poorly implemented, strengthening the construction of accounting system as a technical normative has no effect on the improvement of accounting integrity. On the contrary, when the construction of technical normative systems such as accounting standards lags behind and is difficult to improve significantly in the short term, strengthening the regulatory system can improve the level of accounting integrity.

There are priorities in the system construction of controlling accounting dishonesty. Due to the existence of the critical point of accounting information supervision, it is very important for the improvement of accounting integrity that the supervision system reaches the critical point of supervision. Because when the regulatory system lags behind the level of regulatory critical point, the normative system can not play its due role in accounting integrity. Therefore, for the backward regulatory system environment, we should first strengthen the construction of punitive regulatory system.

China should strengthen the construction of independent audit supervision mechanism, strengthen the supervision role of intermediary institutions, and strengthen the independence of CPA audit. An audit committee shall be

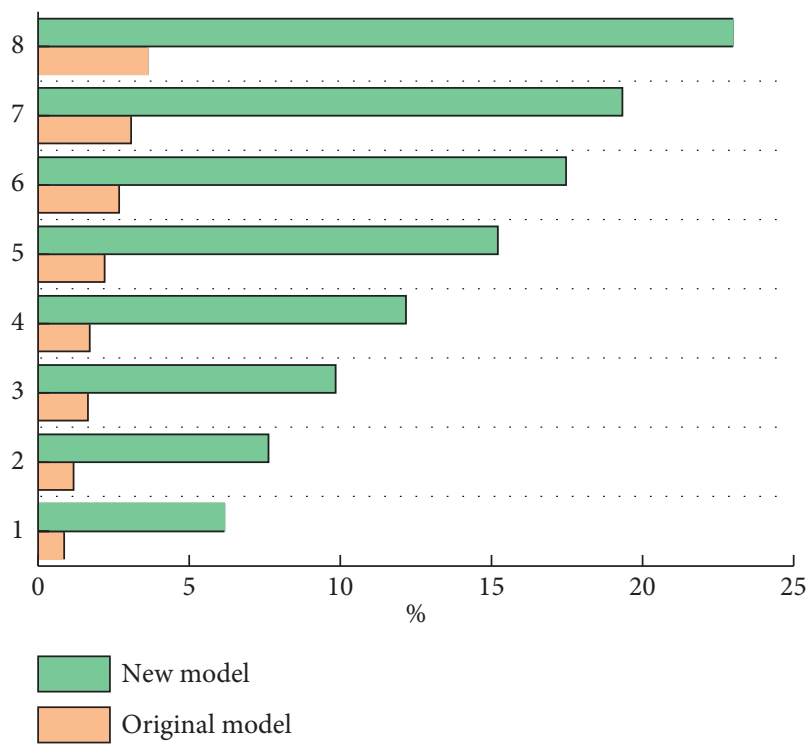

Figure 9: Results trend.

established, which shall be responsible for hiring and replacing accounting firms. And require the company to disclose sufficient reasons when changing the accounting firm. And improve the independent audit standards, provide technical support for certified public accountants to prevent profit manipulation, enhance the operability of the audit standards, and formulate a series of practice standard guidelines matched with specific standards and physical announcements as soon as possible, so as to better implement the independent audit standards, effectively improve the audit quality, strengthen the construction of audit practice team, and strengthen the concept of legal system and professional ethics.

Considering the attribute of public goods of accounting information, when using civil litigation mechanism in this field, its personal cost and social cost will deviate. Therefore, it is necessary to design the system from two aspects of income and cost. From the perspective of income, it is mainly to increase the income expectation of individual private law enforcement, such as prescribing punitive damages, spiritual damages, litigation costs borne by the losing party, etc. In terms of cost, it can usually reduce the cost of private law enforcement, such as the establishment of group litigation or shareholder litigation, and the litigation costs are shared by many individuals with scattered interests. The cost of private law enforcement can be reduced through the arrangement of litigation procedures such as evidence rules, such as the transfer of the burden of proof, lawyers extracting lawyers' fees from the winning proceeds, etc. This encourages individuals to enforce private law. When the court accepts such litigation, the provisions of the preadministrative punishment of the CSRC shall also be repealed as soon as possible. Establish and improve the laws and regulations for legal investigation of accounting dishonests and the legal provisions and punishment measures for the identification of accounting information distortion. The punishment provisions for illegal acts of false accounting reports in the current accounting law, 
the company law, and the Securities Law shall be uniformly revised and the punishment standards shall be unified. In order to more accurately crack down on accounting violations and crimes, the current criminal law can be amended through legislation to increase the relevant charges of crimes in the accounting industry. At the same time, China's civil law system must establish the accounting civil compensation liability system, so that the losses caused by the use of false accounting information can be compensated to the greatest extent, and the accounting fraud can be punished by the administration At the same time of criminal punishment, bear civil liability for compensation, so as to increase the fraud cost of accounting fraudsters and improve the government supervision mechanism in law.

\section{Conclusion}

(1) Based on this, this paper first constructed the grey comprehensive correlation analysis model and analyzed the nature of the model; the model has the order preservation, standardization, and so on; the model also considers the positive and negative correlation between sequences. The research shows that the model overcomes the shortcomings of the existing models, and the comparison with other grey relational analysis models proves that the model has good applicability. In view of the fact that it is relatively difficult to measure the closeness of the relation between the member companies of an enterprise group, this paper uses the grey relation analysis method to construct a measurement model of the grey relation between the member companies of an enterprise group.

(2) The recursive function relation between accumulated sequences is derived from the time response function of NGM $(1,1) k$ model, and the method of direct estimation of parameter value of NGM $(1,1)$ model time response function is given. On this basis, a new NGM $(1,1) k$ model which can simulate both approximately homogeneous and approximately inhomogeneous exponential sequences is constructed. The new model avoids the jump error of model parameter estimation from difference equation to differential equation and theoretically explains the reason why the new model can simulate both homogeneous exponential sequences and inhomogeneous exponential sequences.

(3) Based on the disturbance theory, the stability of the traditional first-order cumulative discrete grey model is analyzed from whether the model satisfies the new information priority principle and least information principle. The reduction error and monotonicity of the model are compared between the first-order cumulative discrete grey model and the fractional cumulative discrete grey model. The relationship between sample size and model stability was explained from the perspective of model stability.

\section{Data Availability}

The data used to support the findings of this study are available from the corresponding author upon request.

\section{Conflicts of Interest}

The author declares no conflicts of interest.

\section{References}

[1] F. Hong, "Discussion on the performance evaluation index system of basic course teaching team in colleges and universities," Asian Agricultural Research, vol. 12, no. 3, pp. 72-74, 2020.

[2] D. C. Ferreira and R. C. Marques, "Malmquist and hicksmoorsteen productivity indexes for clusters performance evaluation," International Journal of Information Technology and Decision Making, vol. 15, no. 5, pp. 1015-1053, 2016.

[3] T. A. Baran, R. G. Baraniuk, A. V. Oppenheim, P. Prandoni, and M. Vetterli, "MOOC adventures in signal processing: bringing DSP to the era of massive open online courses," IEEE Signal Processing Magazine, vol. 33, no. 4, pp. 62-83, 2016.

[4] D. Wu, J. Yan, H. Wang, D. Wu, and R. Wang, "Social attribute aware incentive mechanism for device-to-device video distribution," IEEE Transactions on Multimedia, vol. 19, no. 8, pp. 1908-1920, 2017.

[5] X. Li, S. Tang, L. Xu, H. Wang, and J. Chen, "Two-factor data access control with efficient revocation for multi-authority cloud storage systems," IEEE Access, vol. 5, no. 99, pp. 393-405, 2017.

[6] W. L. Sang and J. Lee, "A comparative study of kakao story and facebook: focusing on use patterns and use motives," Telematics and Informatics, vol. 34, no. 1, pp. 220-229, 2017.

[7] Y. Zeng, J. Liu, K. Sun, and L.-W. Hu, "Machine learning based system performance prediction model for reactor control," Annals of Nuclear Energy, vol. 113, no. 12, pp. $270-278,2018$.

[8] K. Greff, R. K. Srivastava, and J. Koutnik, "LSTM: a search space odyssey," IEEE Transactions on Neural Networks and Learning Systems, vol. 99, no. 10, pp. 1-11, 2016.

[9] G. Misra and J. M. Such, "Pacman: personal agent for access control in social media," IEEE Internet Computing, vol. 21, no. 6, pp. 18-26, 2017.

[10] A. Khedr, G. Gulak, and V. Vaikuntanathan, "Shield: scalable homomorphic implementation of encrypted data-classifiers," IEEE Transactions on Computers, vol. 65, no. 9, pp. 2848-2858, 2016.

[11] J. S. Fredman, L. E. Calvet, and P. Bessiere, "Bayesian inference with muller C-elements," IEEE Transactions on Circuits and Systems I-Regular Papers, vol. 63, no. 6, pp. 895-903, 2016.

[12] X. Font, J. Higham, and G. Miller, "Research engagement, impact and sustainable tourism," Journal of Sustainable Tourism, vol. 11, no. 2, pp. 1-11, 2019.

[13] M. Cetin, I. Zeren, H. Sevik, C. Cakir, and H. Akpinar, "A study on the determination of the natural park's sustainable tourism potential," Environmental Monitoring and Assessment, vol. 190, no. 3, pp. 167-178, 2018.

[14] P. Látková and C. A. Vogt, "Residents' attitudes toward existing and future tourism development in rural communities," Journal of Travel Research, vol. 51, no. 1, pp. 50-67, 2016.

[15] H. Peng, H. Yong, and F. Xu, "Evolutionary analysis of sustainable tourism," Annals of Tourism Research, vol. 69, no. 15, pp. 76-89, 2018. 
[16] D. Stylidis, "Place attachment, perception of place and residents' support for tourism development," Tourism Planning \& Development, vol. 13, no. 1, pp. 1-23, 2018.

[17] R. Scheyvens, "Linking tourism to the sustainable development goals: a geographical perspective," Tourism Geographies, vol. 20, no. 2, pp. 1-2, 2018.

[18] K. I. Kakoudakis and S. Mccabe, "Social tourism as a modest, yet sustainable, development strategy: policy recommendations for Greece," Journal of Policy Research in Tourism, Leisure and Events, vol. 13, no. 15, pp. 1-15, 2018.

[19] A. Virapongse, S. Brooks, E. C. Metcalf et al., "A social-ecological systems approach for environmental management," Journal of Environmental Management, vol. 178, no. 178, pp. 83-91, 2016.

[20] D. Mendola and S. Volo, "Building composite indicators in tourism studies: measurements and applications in tourism destination competitiveness," Tourism Management, vol. 59, no. 16 , pp. 541-553, 2017.

[21] J. D. Hunt, "Image as a factor in tourism development," Tourism Recreation Research, vol. 13, no. 3, pp. 1-7, 2016.

[22] A. Sanches-Pereira, B. Onguglo, H. Pacini, M. F. Gómez, S. T. Coelho, and M. K. Muwanga, "Fostering local sustainable development in Tanzania by enhancing linkages between tourism and small-scale Agriculture," Journal of Cleaner Production, vol. 162, no. 19, pp. 1567-1581, 2017.

[23] P. V. Mathew and S. Sreejesh, "Impact of responsible tourism on destination sustainability and quality of life of community in tourism destinations," Journal of Hospitality and Tourism Management, vol. 31, no. 17, pp. 83-89, 2017.

[24] H. Cui, Y. Guan, and H. Chen, "A novel advancing signal processing method based on coupled multi-stable stochastic resonance for fault detection," Applied Sciences, vol. 11, no. 12, pp. 53-85, 2021.

[25] Z. H. Zhang, F. Min, and G. S. Chen, "Tri-partition state alphabet-based sequential pattern for multivariate time series," Cognitive Computation, vol. 2021, pp. 1-19, 2021.

[26] A. L. Calear and P. J. Batterham, "Suicidal ideation disclosure: patterns, correlates and outcome," Psychiatry Research, vol. 278, no. 16, pp. 1-6, 2019.

[27] S. A. Grilo, M. Catallozzi, J. S. Santelli et al., "Confidentiality discussions and private time with a health-care provider for youth, United States, 2016," Journal of Adolescent Health, vol. 64, no. 3, pp. 311-318, 2019.

[28] M. A. Hom, I. H. Stanley, M. C. Podlogar, and T. E. Joiner, "“A Are you having thoughts of suicide?" examining experiences with disclosing and denying suicidal ideation," Journal of Clinical Psychology, vol. 73, no. 10, pp. 1382-1392, 2017.

[29] P. N. Pfeifer, C. King, and M. Ilgen, "Development and pilot study of a suicide prevention intervention delivered by peer support specialists," Psychological Services, vol. 16, no. 3, pp. 360-371, 2019.

[30] J. D. Ribeiro, J. C. Franklin, K. R. Fox et al., "Self-injurious thoughts and behaviors as risk factors for future suicide ideation, attempts, and death: a meta-analysis of longitudinal studies," Psychological Medicine, vol. 46, no. 2, pp. 225-236, 2016.

[31] S. A. Rosenrot and S. P. Lewis, "Barriers and responses to the disclosure of non-suicidal self-injury: a thematic analysis," Counselling Psychology Quarterly, vol. 33, no. 2, pp. 121-141, 2020.

[32] J. B. Singer, T. A. Erbacher, and P. Rosen, "School-based suicide prevention: a framework for evidence-based practice," School Mental Health, vol. 11, no. 1, pp. 54-71, 2019.

[33] M. Aghajani and M. Adloo, "The effect of online cooperative learning on students' writing skills and attitudes through
Telegram application," International Journal of Instruction, vol. 11, no. 10, pp. 433-448, 2018.

[34] I. Badi, D. Pamucar, and D. Pamucar, "Supplier selection for steelmaking company by using combined Grey-Marcos methods," Decision Making: Applications in Management and Engineering, vol. 3, no. 2, pp. 37-48, 2020.

[35] A. Si, S. Das, and S. Kar, "An approach to rank picture fuzzy numbers for decision making problems," Decision Making: Applications in Management and Engineering, vol. 2, no. 2, pp. 54-64, 2019.

[36] S. D. Guo, S. F. Liu, and Z. G. Fang, "Multi-attribute decision making model based on the kernel and the degree of greyness of the interval grey numbers," Control and Decision, vol. 31, no. 6, pp. 1042-1046, 2016.

[37] S. M. Teki, B. Banothu, and M. K. Varma, "An un-realized algorithm for effective privacy preservation using classification and regression trees," Revue d'Intelligence Artificielle, vol. 33, no. 4, pp. 313-319, 2019.

[38] S. Zhang, "Classification of urban land use based on graph theory and geographic information system," Ingénierie des Systèmes d'Information, vol. 24, no. 6, pp. 633-639, 2019.

[39] S. Q. Jiang, S. F. Liu, Z. X. Liu, and Z. G. Fang, "The incidence consistence decision model of interval grey number based on the information decomposition," Control and Decision, vol. 32, no. 1, pp. 111-116, 2017.

[40] Z. X. Liu, S. F. Liu, and Z. G. Fang, "Decision making model of grey comprehensive correlation and relative close degree based on kernel and greyness degree," Control and Decision, vol. 32, no. 8, pp. 1475-1480, 2017.

[41] Y. L. Li, X. L. Yin, and J. Yang, "Multi-attribute group decision making model based on kernel and degree of greyness of interval grey numbers," Fire Control and Command Control, vol. 42, no. 3, pp. 17-20, 2017.

[42] M. Chen, Y. Ding, D. Wu et al., "Grey relational analysis of contaminants governing foaming behavior in desulfurization solution for high-sulfur natural gas," Petroleum Science and Technology, vol. 35, no. 24, pp. 2249-2254, 2017. 